\title{
Telenovela e identidade étnica: estudo da recepção de suave veneno entre camponeses descendentes de alemães e italianos
}

\section{Jiani Adriana Bonin *}

\begin{abstract}
Resumo
$\mathrm{O}$ artigo trata da relação entre identidade étnica e recepção de telenovela. Ancorado no entendimento da recepção como um processo, que ganha inteligibilidade a partir da cultura, no qual operam mediações, o trabalho tem como objetivo estudar o papel da identidade étnica como mediação na recepção de um gênero específico, a telenovela. A pesquisa empírica, de natureza qualitativa, focaliza a recepção da telenovela Suave Veneno (Rede Globo) por famílias camponesas descendentes de imigrantes alemães e italianos do municipio de Urubici-SC.

Palavras-chave: Recepção de TV, identidade étnica, mediações, telenovela.
\end{abstract}

\section{Introdução}

O propósito deste artigo é apresentar e analisar os resultados de uma pesquisa empírica que procurou estudar o papel da identidade étnica no processo de recepção de telenovela e na construção de sentidos que aí tem lugar. A pesquisa situa-se na perspectiva da recepção e a identidade étnica é tomada como fonte de mediação na recepção televisiva. A pesquisa empírica focalizou a recepção da telenovela Suave Veneno (Rede Globo, janeiro-setembro/99) por famílias camponesas alemãs e italianas de Urubici (SC).'

\section{Perspectivas teóricas da pesquisa}

$\mathrm{Na}$ apresentação das perspectivas teóricas que fundamentam a investigação, problematizo primeiramente o processo de construção

* Dra em comunicaçăo e profa. da Universidade do Vale do Rio dos Sinos UNISINOS

Comun. Inf., v. 6, n. 1, p.57-72, jan./jun. 2003 


\section{8}

de significações na recepção a partir das mediações culturais. Num segundo momento, busco avançar no estabelecimento de uma perspectiva para estudar a identidade étnica e compreender seu papel no processo de produção de sentidos na recepção, procurando levar em conta também a centralidade crescente dos fenômenos de midiatização na vida social. ${ }^{2}$

$\mathrm{Na}$ perspectiva teórica que adoto para pensar a recepção, um ponto importante é que seu entendimento passa pela compreensão do papel da cultura e das identidades dos grupos estudados no processo. A recepção é vista como um processo complexo, onde o sentido se constrói na inter-relação entre produtos midiáticos e receptores sócioculturalmente situados. Para usar a expressão de Jesús Martín Barbero (1997), no processo de produção de sentidos operam mediações; vários autores latino-americanos, seguindo esta linha, vem trabalhando para entender estes "lugares" a partir dos quais se pode compreender a inter-relação entre produtos midiáticos e receptores no âmbito da recepção. ${ }^{3}$ Uma das fontes de mediação implicadas no processo de produção de sentidos para os produtos midiáticos refere-se à classe social. Tomada como lugar que permite considerar a articulação estrutural da sociedade, a classe manifesta-se nos usos e na recepção via habitus de classe ${ }^{4}$ conceito cunhado por Bourdieu que permite pensar a configuração de esquemas mais ou menos inconscientes de percepção, de ação e de valoração que se inscrevem nos sujeitos a partir do lugar social que ocupam e que se configuram no processo de socialização. ${ }^{5}$ Esta perspectiva, embora fecunda, impossibilita entretanto a captura de processos e potenciais de transformação embutidos nas práticas de recepção. Vale considerar também outros referenciais, como a proposta de Certeau (1996), que possibilita abrir a reflexão para divisar possibilidades de reapropriação dos produtos massivos, de fabricação de outros sentidos, distintos daqueles imprimidos na produção. Nessa perspectiva, o consumidor está inscrito em relações de poder, mas não é um ator passivo. Também instaura uma outra produção, fabrica num espaço que é do outro, com os elementos que a ordem dominante lhe impõe. Esta fabricação se faz notar na forma de empregar os produtos, na apropriação. Aqui, a cultura popular formula-se e expressa-se em artes de fazer. É preciso considerar também os cruzamentos que se operam entre o hegemônico e o popular, as seduções, as cumplicidades, as ambigüidades destas relações, via aberta nos estudos de recepção pela incorporação do conceito de hegemonia de Gramsci

Comun. Inf., v. 6, n. 1, p.57-72, jan./jun. 2003 
A classe social não esgota entretanto a explicação das diferenças que se observam na recepção. Fenômenos culturais e simbólicos que transcendem o recorte de classe, importantes na atualidade, também operam mediações na recepção. Entram aqui as competências culturais ordenadas pelos grupos étnicos, objeto desta pesquisa, pelas culturas regionais, pelo gênero, pela geração, pelas culturas juvenis, pelas tribos urbanas, pelas culturas imigrantes, que vem sendo estudadas por vários autores. ${ }^{6} \mathrm{O}$ que se coloca a partir destes trabalhos é a importância que outras categorias, reveladoras de competências culturais diferentes daquelas conformadas pela classe social, adquirem na inteligibilidade do processo de produção de sentidos na recepção midiática. É preciso considerar também as mestiçagens, as hibridações que se manifestam nas culturas atuais, potencializadas pelo processo de globalização e particularmente pela relação com a mídia.? A partir desta perspectiva e na impossibilidade de abarcar todas as categorias que configuram mediações nos processos de recepção, busco refletir neste trabalho sobre a mediação operada pela identidade étnica.

$\mathrm{Na}$ ordenação de uma proposição sobre os fenômenos da etnicidade e da identidade étnica, julgo pertinentes os diálogos com autores da antropologia que empreendem uma revisão destes conceitos. Na definição desta proposta, dialogo com a contribuição introduzida por Fredrik Barth, considerando também proposições de outros autores no sentido de captar as especificidades do que se define como uma identidade propriamente étnica.

Acolhendo elementos da proposição de Barth (1998), na definição de grupo étnico parto da visão de que configura uma forma de organização social, que expressa uma identidade diferencial nas relações com outros grupos e com a sociedade mais ampla. A identidade étnica é utilizada como forma de estabelecer os limites do grupo e de reforçar a sua solidariedade. Mas, se as categorias étnicas tomam as diferenças culturais em consideração, não é a soma das diferenças culturais "objetivas" que determinam o conteúdo da identidade étnica e sim aquelas que os atores consideram significativas, que são realçadas e tornadas organizacionalmente relevantes. Certos elementos culturais são utilizados pelos atores como sinais emblemáticos da diferença. Nesta concepção, a continuidade dos grupos étnicos não é explicada em termos de manutenção da sua cultura tradicional, mas depende da manutenção dos limites do grupo, da contínua dicotomização entre

Comun. Inf., v. 6, n. 1, p.57-72, jan./jun. 2003 


\section{0}

membros e não membros. Desta forma, os traços culturais que demarcam os limites do grupo podem mudar e a cultura pode ser igualmente objeto de transformações, sem que isso implique o esvaziamento da solidariedade étnica. O mérito desta proposta está em deslocar a concepção estática de grupo étnico como suporte de cultura e, por conseguinte, da identidade étnica como uma identidade fixa, essencialista, para uma concepção dinâmica do grupo étnico e da identidade étnica, introduzindo portanto, a história. Também permite pensar que a cultura e a identidade étnicas podem se transformar na relação com as mídias, sem que isto implique a dissolução destas identidades.

Tomo a identidade étnica como um sistema de representação cultural - nos termos propostos por Hall (1999) - construído pelos grupos étnicos em situações específicas e que pode ser objeto de transformação a partir de processos como a midiatização. Levando em conta contribuições de outros autores, é possível propor elementos para abarcar especificidades de uma identidade propriamente étnica. Assim, considero que o sistema de categorização da identidade étnica fundamenta-se numa origem comum suposta, questão recuperada da contribuição weberiana sobre os grupos étnicos, que propõe que a crença subjetiva na origem comum constitui um laço característico da etnicidade. ${ }^{8}$

Com respeito à questão do que ocorre com as identidades culturais no processo de globalização, situo-me numa perspectiva que considera que este processo tem um efeito pluralizante sobre as identidades, produzindo novas possibilidades e novas posições de identificação; tornando-as mais posicionais, plurais e diversas, menos fixas, unificadas ou trans-históricas. Repensar a identidade em tempos de globalização passa por concebê-la como identidade multicultural, que se nutre de vários repertórios, que pode ser multilíngue, nômade, transitar, deslocar-se, reproduzir-se em lugares distantes do território onde nasceu como forma identitária. É nesta via que caminham as proposições de autores como Hall (1999) e García Canclini (1997b), guardadas as suas especificidades.

Neste sentido, trabalho com a hipótese de que a etnicidade persiste como fenômeno e que a identidade étnica constitui ainda uma forma de identificação pertinente para os atores sociais, mas está sendo, em maior ou menor grau, remodelada no processo de globalização. É provável que esteja oscilando entre a tradição e a tradução ${ }^{9}$ e que a

Comun. Inf., v. 6, n. 1, p.57-72, jan./jun. 2003 
mídia tenha um papel fundamental na constituição de processos de remodelação e de tradução destas identidades.

Em relação ao processo de recepção, minha hipótese de trabalho é que os telespectadores se valem do atual sistema de representação da identidade na construção de significações para as proposições da telenovela. Ele é "acionado", operando processos de reconhecimento e de distinção na recepção da telenovela. Neste processo, a telenovela também contribui para movimentos de reordenamento da cultura e da identidade étnicas, conformando processos de fortalecimento e,ou de remodelação de traços identitários destes grupos.

\section{Procedimentos metodológicos}

A telenovela pesquisada foi a Suave Veneno ${ }^{10}$, exibida pela Rede Globo no período de 18 de janeiro a 17 de setembro de 1999.

A pesquisa de recepção foi realizada no município de Urubici, Santa Catarina. A amostra, de natureza qualitativa, foi construída no sentido de introduzir diferentes situações em relação à identidade étnica dentro de uma condição de classe específica (camponeses). Optei por compor uma amostra de famílias alemãs e italianas, predominantes no município estudado, assim organizada: duas famílias de casamento endogâmico (uma família alemã, uma italiana) e uma de casamento misto (italoalemã). Na escolha das famílias, considerei critérios relativos à assistência da telenovela estudada e à tipicidade de caracteristicas da condição camponesa (condição de posse da terra), étnica (famílias pertencentes aos grupos étnicos alemães e italianos) e familiar (estrutura nuclear e relações de proximidade com a familia extensa) no município estudado, que pude averiguar através de uma pesquisa quantitativa prévia, onde apliquei formulários com $10 \%$ das famílias camponesas do município, escolhidas aleatoriamente.

A escolha da telenovela como produto televisivo a ser estudado foi feita considerando ser este um dos gêneros televisivos mais vistos entre os camponeses do município; a eleição da "novela das oito" da Rede Globo também pautou-se na constatação de que a emissora e a telenovela são as mais assistidas entre os camponeses do município estudado, de acordo com a já mencionada pesquisa quantitativa.

A opção pela família como unidade de análise levou em conta a verificação de que é onde se dá o consumo de TV e de telenovela entre os camponeses do município estudado, feita na pesquisa

Comun. Inf., v. 6, n. 1, p.57-72, jan./jun. 2003 


\section{2}

quantitativa. Levei em conta também o papel que a unidade familiar desempenha na constituição e preservação da identidade étnica, reportado por autores como Zveibil (1980).

A estratégia metodológica organizada para a coleta de dados explorou a combinação de várias modalidades de técnicas de pesquisa, o que permite captar dados de diferentes angulações, tal como propõem Lopes et al. (2002)" e Maldonado (2002). Foram utilizadas a observação etnográfica do cotidiano familiar e do momento de recepção da telenovela, além de modalidades diferentes de entrevista (semiestruturada, focalizada) para obter dados sobre a mediação estudada e relatos sobre a telenovela. A coleta de dados foi realizada no período de março a dezembro de 1999. O tratamento dos dados foi equacionado através de duas etapas: a transcrição dos registros gravados e a classificação dos dados, esta última operação realizada com o auxílio do software Winmax, que facilitou a realização da análise descritiva. $^{12}$

\section{A mediação da identidade étnica na recepção}

Os dados levantados na pesquisa permitem dizer que a identidade social das famílias pesquisadas organiza-se em dois planos interrelacionados: o plano relativo à identidade que expressa a condição social de camponeses e o plano da identidade étnica. Para o propósito deste artigo, vou me ater somente à discussão do plano propriamente étnico da identidade.

Um dos pontos centrais que a pesquisa revelou diz respeito à conformação do grupo étnico e de seus limites. Inicialmente eu havia presumido que estariam configurados grupos étnicos em torno das distintas procedências nacionais de imigração. Entretanto, na situação estudada, elaborou-se uma identidade mais abrangente, que articula as subdivisões relacionadas a procedências nacionais, ainda persistentes como diferenciações internas a esta identidade. A categoria origem constitui a forma nativa de auto-definição que expressa esta identidade comum. Neste plano, a alteridade constrói-se na relação com os brasileiros, denominação que engloba os demais habitantes do município que não descendem de imigrantes europeus.

Em se tratando das categorias que atualmente definem a pertença ao grupo étnico, um critério fundamental é revelado na própria expressão nativa que denomina esta identidade: para ser considerada

Comun. Inf., v. 6, n. 1, p.57-72, jan./jun. 2003 
do grupo, a pessoa tem que ter origem, o que significa ser descendente de imigrantes europeus que participaram da colonização. Isto remete àquilo que, nos termos de Weber, constitui o traço característico da identidade étnica, a crença na origem comum.

Um segundo conjunto de traços considerados distintivos aparece sob a forma de representações associadas ao trabalho, à economia, ao empreendimento e ao planejamento do futuro. ${ }^{13}$ Em relação ao trabalho, os de origem consideram-se mais trabalhadores como também mais caprichosos, mais zelosos em relação às suas "obrigações" do que os brasileiros. Estas qualidades são expressas através de descrições que enfatizam o cuidado com plantações, animais, ferramentas e implementos. Por oposição, os brasileiros são vistos como menos trabalhadores e até como "vadios"; também como menos caprichosos e menos dedicados em relação ao trabalho. Estas representações têm ancoragem em práticas que remetem a um ethos do trabalho: nas três famílias pesquisadas, o trabalho revela-se como dimensão fundamental da vida, cuja centralidade pode ser observada tanto no tempo que abarca nas rotinas cotidianas como na sua ordenação. É importante considerar que o trabalho e a poupança são também características culturais mobilizadas em relação ao plano da identidade camponesa. ${ }^{14}$

As distinções consideradas difundem-se de modo bastante homogêneo nas representações dos pais das três famílias. Também aparecem incorporadas na geração dos filhos, havendo na geração jovem apenas um caso de questionamento destes critérios. Agora, se podemos afirmar que estas distinções estão, em maior ou menor grau, presentes na geração dos filhos, vale considerar certos matizes nesta incorporação. Durante a pesquisa, pude constatar entre os jovens uma insatisfação com respeito à definição da vida muito centrada no trabalho, notadamente aqueles das familias alemã e italiana. Tais constatações sinalizam para a incorporação de referentes vindos de outros repertórios culturais às representações identitárias, que podem introduzir reordenamentos neste traço cultural também em termos das práticas.

Outro traço reivindicado pelos de origem como distintivo em relação aos brasileiros diz respeito à orientação para a poupança. "Ser seguro" é a expressão nativa que revela a orientação à economia, que deve perpassar o manejo de todos os recursos. Na ótica das famílias entrevistadas, o dinheiro deve ser gasto com moderação, de acordo com uma ordem de necessidades; os recursos devem ser utilizados de

Comun. Inf., v. 6, n. 1, p.57-72, jan./jun. 2003 


\section{4}

modo que se tenha para o dia de amanhã; cuidar do que se tem também implica uma atitude de poupança. A orientação para a poupança aparece ligada ao empreendimento e ao planejamento do futuro. Neste sentido, os de origem distinguem-se dos brasileiros por considerarem-se pessoas empreendedoras, que "pensam no futuro" e "trabalham para adquirir", para "progredir na vida", para "dar conforto e segurança para a família". Por contraste, os brasileiros são vistos como pessoas que gastam todo o dinheiro que ganham, não tendo a preocupação de guardar para os tempos de escassez, de planejar o futuro. Estas representações apresentam-se incorporadas de modo bastante homogêneo e consistente na geração dos pais. Entre os filhos sua disseminação é mais fragmentada. Observam-se entre os jovens aspirações por mais lazer e por um acesso maior ao consumo que contestam definições rígidas de poupança e de planejamento do futuro.

Embora se possa dizer que a poupança é um traço que orienta as práticas das famílias pesquisadas, pode-se ver que já na geração dos pais expressam-se redefinições em relação ao que se coloca como da ordem do necessário, produto de sua inserção no campo do consumo. Em todas as casas encontramos a presença de eletrodomésticos, meios de comunicação e produtos variados de mercado. Entre os jovens evidenciam-se práticas de consumo que relativizam o critério da poupança, como a valorização de certas marcas na compra de tênis, sapatos, roupas - formas como o global penetra o local.

Os dados da pesquisa permitem dizer que a telenovela tem um papel nestes reordenamentos no sentido de que contribui para introduzir novos referentes, como aqueles relacionados ao campo do consumo. Os relatos dos membros das famílias pesquisadas permitem ver que a telenovela contribui para estimular e promover aspirações de consumo.

Passemos agora à análise de como estes critérios de distinção da identidade estão implicados na produção de sentidos para a telenovela estudada. Analisando os relatos dos membros das famílias pesquisadas sobre o trabalho dos personagens na telenovela e sua relação com $a$ realidade vivida, vemos que estas matrizes da identidade funcionam como chaves de leitura, sendo a base para classificações do tipo nós/ eles, ou seja, permitem estabelecer reconhecimentos/distinções em relação aos personagens. Esta lógica se faz presente nos relatos sobre todos os personagens abordados pelos entrevistados.

A título de exemplo, consideremos os relatos das famílias referentes

Comun. Inf., v. 6, n. 1, p.57-72, jan./jun. 2003 
a alguns personagens que se mostraram relevantes na recepção. $\mathrm{O}$ personagem Valdomiro, o mais comentado da telenovela, é unanimemente visto como a encarnação do critério de pertença relativo ao trabalho, o que pode ser percebido pelas qualificações de "trabalhador", "batalhador", "sério no serviço", "honesto", "compromissado e amoroso com o trabalho". Também expressa para todos os pesquisados os critérios de poupança, empreendimento e planejamento do futuro, o que pode ser percebido nas representações dele como um homem que "lutou para adquirir, para ir pra frente". Nestes relatos e na identificação do personagem por todos como o mais representativo da identidade de origem, podemos ver que ele adquire a força de figura símbolo da identidade. Já a personagem Nana, também bastante comentada em relação ao trabalho entre vários entrevistados, figura como alteridade em relação aos critérios que estamos examinando. É considerada uma "pessoa que não trabalha", que "esbanja dinheiro", que "gasta mais do que possui", que "faz dividas" e que conta com o dinheiro alheio para seu sustento, representando o oposto das virtudes étnicas trabalho, poupança, empreendimento e planejamento do futuro.

Para finalizar estes exemplos ilustrativos, consideremos os relatos sobre os personagens Clarice e Cláudio, focalizados por serem representantes dos denominados brasileiros na telenovela. Eles revelam a força dos estereótipos sobre este grupo. Por serem considerados pela maioria como bons, honestos, trabalhadores, possuidores de uma condição social melhor, "estudados", os personagens Cláudio e Clarice não se encaixam nos estereótipos do brasileiro "vadio", "relaxado", "pobre"; eles acabam sendo vistos como atípicos, como "negros que fazem papel de branco", de "pessoa de origem". Neste caso, é possível ver que os estereótipos resistem ao confronto com personagens da telenovela que apresentam características distintas daquelas atribuídas ao grupo, funcionando como chaves da sua classificação como diferentes, não representativos.

Os dados evidenciam a força dos critérios distintivos, que permanecem resistentes no encontro com a telenovela. Isto pode ser percebido no modo como os pesquisados operam as classificações dos personagens, separando nítida e marcadamente os semelhantes (nós) e os distintos (eles). Também revelam a força dos estereótipos atribuídos ao grupo dos brasileiros, nas leituras dos personagens Cláudio e Clarice. Neste caso, apesar de propor personagens que

Comun. Inf., v. 6, n. 1, p.57-72, jan./jun. 2003 
fogem do estereótipos atribuídos a este grupo, a telenovela não consegue questionar estes núcleos duros de sentido presentes no sistema de representação do grupo de origem. Notamos também que a telenovela apresenta personagens capazes de operar o reconhecimento identitário no grupo de origem, ao trabalhar no texto matrizes fundamentais desta identidade. Aqui vemos fazer sentido a proposição de Martín Barbero (1997) de que o segredo da força do melodrama está nos elementos que nele ancoram a identificação e o reconhecimento cultural, nas matrizes culturais que incorpora e de Buonanno (1999), que concebe os textos de ficção (como a telenovela) como textos de identidade.

A religiosidade é outro traço cultural mobilizado na distinção entre os de origem e os brasileiros. Entretanto, se é reivindicada como elemento distintivo, também é apontada como característica cultural em redefinição, na medida em que os sujeitos identificam certa perda de terreno das práticas religiosas no cotidiano. De acordo com os pais, esta perda de terreno manifesta-se de modo mais acentuado na geração dos filhos, reconhecimento que leva alguns a considerar a possível perda do valor contrastivo desta característica em relação aos brasileiros. É significativo o fato de que este critério não esteja presente na representação de alguns jovens, como os filhos mais novos da família ítalo-alemã.

A reivindicação da religiosidade como um critério de pertencimento apoia-se num conjunto de práticas religiosas cotidianas, nas três famílias pesquisadas, a despeito de nuances na sistematicidade destas práticas. ${ }^{15}$

Vejamos agora como este critério de distinção opera sua mediação na produção dos sentidos para a telenovela estudada. De modo geral, o que se nota ao percorrer os relatos sobre a telenovela é uma interpretação de que havia pouca religiosidade no modo de vida dos personagens, unânime entre os entrevistados. Esta visão é fundamentada basicamente no entendimento de uma quase ausência de práticas religiosas no cotidiano dos personagens, como rituais religiosos institucionais - a exceção que reconhecem são os casamentos - de práticas como a oração e a conversa sobre religião em família. Com base nestes relatos, pode-se argumentar que os personagens da telenovela estudada constituem-se na alteridade que permite a eles diferenciarem-se como mais religiosos e mais praticantes. Assim, vemos este critério ser mobilizado na relação com os personagens, operando sua mediação na construção dos sentidos. Isto se dá na medida em que as representações relativas a este critério funcionam como um

Comun. Inf., v. 6, n. 1, p.57-72, jan./jun. 2003 
referencial a partir do qual se estabelecem processos de reconhecimento/ distinção na relação com os personagens.

Outra questão que se impõe à reflexão é se a telenovela pode estar contribuindo para operar mudanças em relação ao critério religiosidade. Esta é uma questão complexa, mas a pesquisa possibilita ver que a TV e a telenovela estão de algum modo implicadas nos processos de mudança. Um primeiro modo de implicação é que a TV e a telenovela passaram a fazer parte dos momentos de convivência familiar dentro de casa, deslocando outras práticas que aí tinham lugar, entre elas as de oração em família. No plano das representações, a telenovela parece estar contribuindo para abrandar concepções rígidas e etnocêntricas de religião, na medida em que fornece exemplos de outros modos de vivência da espiritualidade que penetram no cotidiano dos receptores. No caso da telenovela estudada, o personagem Ualber estabelece uma relação tensa e de algum modo questionadora com muitos dos membros das famílias pesquisadas, na medida em que vivencia sua espiritualidade de modo distinto deles mas, ao mesmo tempo, expressa práticas e valores semelhantes aos deles. Isto contribui para que muitos pesquisados reconheçam-se nele e aceitem-no como religioso. Além disso, personagens que não demonstram o seguimento de práticas religiosas institucionais mas expressam valores religiosos (por exemplo Fortunato e Lavínia) alcançam reconhecimento entre os pesquisados, ajudando a legitimar novos modos de relacionamento com a religião, não tão rígidos. Neste caso, confirma-se a proposição de que a relação com outros referentes culturais advindos da telenovela, contribui para que as identidades se tornem menos fixas, mais posicionais e móveis.

As distinções entre os de origem e os brasileiros também são firmadas a partir de atributos raciais. Os brasileiros são identificados por características fenotípicas, em particular a cor: são "negos", "morenos", "misturados", para usar expressões nativas; alguns referem-se também à baixa estatura e ao tipo de cabelo. Na prática, os chamados índices operatórios - noção que, de acordo com Poutignat e Streiff-Fenart (1998), remete aos indicadores imediatamente utilizados para fazer o reconhecimento da pertença em uma dada situação utilizados pelo grupo para reconhecerem os brasileiros inicialmente são as características fenotípicas, ainda que os critérios de distinção mais importantes sejam culturais. Os atributos raciais também mediam a relação com a telenovela, funcionando como modo de reconhecimento primeiro da pertença étnica dos personagens.

Comun. Inf., v. 6, n. 1, p.57-72, jan./jun. 2003 
Para finalizar, gostaria de retomar o percurso do trabalho e sumarizar os resultados obtidos. No estudo da mediação da identidade étnica na recepção da telenovela, procurei situar o sistema de representações do grupo pesquisado em termos das categorias de pertencimento, discutir suas relações com as práticas e desvendar como participam da produção de sentidos para a telenovela. A pesquisa permitiu identificar como categorias chave de pertencimento/distinção do sistema de representação da identidade étnica o trabalho, o empreendimento, a poupança e o planejamento do futuro, além da religiosidade. Revelou ainda que estas categorias operam mediações significativas na recepção da telenovela, funcionando como sistemas de referência a partir dos quais personagens e situações são interpretados, o que confirma os pressupostos com os quais trabalhei na pesquisa. Estas categorias representativas revelaram-se persistentes no confronto com a telenovela. Entretanto, também foi verificado que as relações com os meios de comunicação em geral e com a telenovela em particular introduzem novos referentes culturais que questionam a rigidez de representações relativas à identidade étnica, particularmente entre os jovens, produzindo misturas culturais. Neste sentido, confirmam-se também as proposições relacionadas aos processos de descentramento e de hibridação da identidade, catalisados pela introdução de novos referentes culturais através da TV, em particular, reveladas no estudo, da telenovela.

\section{Abstract}

The article deals with the relationship between ethnic identity and the reception of television soap operas/dramas. Working with an understanding of reception as a process, which gains intelligibility based on the culture, in which mediation operates, the article has the objective of examining the role of ethnic identity as mediation in the reception of a specific genre, the television soap opera/drama. The qualitative empirical research, is focused on the reception of the soap opera/drama Suave Veneno (Rede Globo) by rural families descending from Germans and Italians immigrants in the municipality of Urubici-SC. Brazil.

Key words: TV reception, ethnic identity, mediation, soap opera/drama.

\section{Notas}

${ }^{1}$ Este trabalho foi elaborado levando em conta proposições e dados da minha Tese de Doutorado (Bonin, 2001).

${ }^{2}$ A noção de midiatização atenta para as transformações que se operam nas práticas sociais com a existência dos meios, seja nas suas modalidades de funcionamento institucional, nos mecanismos de tomada de decisão e nos hábitos de consumo. Esta

Comun. Inf., v. 6, n. 1, p.57-72, jan./jun. 2003 
noção vem sendo incluída na reflexão de autores como Eliseo Verón, Antônio Fausto Neto e Maria Cristina Mata. Ver neste sentido Verón (1997), Mata (1999) e Fausto Neto (1999).

${ }^{3}$ Entre eles Martín Barbero, Guilhermo Orozco Gómez, Jorge Gonzáles, Maria Immacolata Lopes, Denise Cogo e Pedro Gomes, Efendy Maldonado, Jiani Adriana Bonin. Ver por exemplo Martín Barbero (1987, 1997), Orozco Gómez (1991, 1992, 1993), González (1991a, 1991b, 1993a, 1993b), Lopes et al. (2002), Bonin (1996, 2001, 2002), Gomes e Cogo (1998) e Cogo (2002).

${ }^{4} \mathrm{O}$ conceito de habitus é desenvolvido em Bourdieu (1991, 1994a e 1994b).

${ }^{5}$ A classe social é vista como lugar de compreensão da recepção em trabalhos de autores como Lopes (1995), Lopes et al. (2002) e Leal (1986).

${ }^{6}$ Vários autores apontam a importância destas categorias para compreender a recepção. A cultura e a identidade étnica são vistas por Martín Barbero como referenciais de mediação importantes na recepção, cuja operação foi por mim estudada em trabalho anterior (Bonin 2001), por Ronsini (2002) e, no que se refere à memória identitária, por Strohschoen (2003). As identidades regionais e seu papel na recepção vem sendo estudados por Ronsini (2001) e Jacks (1993). O papel das identidades imigrantes vem sendo pesquisado por Cogo (2002).

${ }^{7}$ Conceitos trabalhados respectivamente por Martín Barbero (1997) e García Canclini (1997a).

${ }^{8}$ Weber (1971), citado por Poutignat e Streiff-Fenart (1998).

${ }^{9} \mathrm{~A}$ tradução é um conceito que procura descrever "aquelas formações de identidade que atravessam e intersectam as fronteiras naturais, compostas por pessoas que foram dispersadas para sempre da sua terra natal. Essas pessoas retém fortes vínculos com seus lugares de origem e suas tradições, mas sem a ilusão de um retorno ao passado. Elas são obrigadas a negociar com as novas culturas em que vivem, sem simplesmente serem assimiladas por elas e sem perder completamente suas identidades. Elas carregam os traços das culturas, das tradições, das linguagens e das histórias particulares pelas quais foram marcadas. A diferença é que elas não são e nunca serão unificadas no velho sentido, porque elas são, irrevogavelmente, o produto de várias histórias e culturas interconectadas, pertencem a uma e, ao mesmo tempo, a várias "casas" (e não a uma casa em particular)". (Robins, citado por Hall, 1999, p.88-89).

${ }^{10}$ A telenovela Suave Veneno foi escrita por Aguinaldo Silva, Ângela Carneiro, Maria Helena Nascimento, Filipe Miguez e Fernando Rebelo, com a colaboração de Marília Garcia e dirigida por Daniel Filho e Ricardo Waddington.

"Fui membro da equipe que realizou a pesquisa publicada neste livro (Lopes et al, 2002), o que me proporcionou experienciar a potencialidade do uso de uma estratégia multimetodológica com combinação de várias modalidades de técnicas de coleta de dados, ali desenvolvida, experiência que marcou minha pesquisa de doutorado, da qual extraio proposições e dados discutidos neste artigo.

${ }^{12} \mathrm{O}$ Winmax é um software desenhado para auxiliar o tratamento de dados qualitativos, atuando nas operações de classificação e de categorização. O programa foi desenvolvido por Udo Kckartz, pesquisador alemão com formação em sociologia. De forma bastante simplificada, pode-se dizer que ele substitui a atividade manual básica de cortar e colar os segmentos de um texto.

${ }^{13}$ As pesquisas de Seyferth $(1976,1986,1993)$ e de Kruger (1995) também demons-

Comun. Inf., v. 6, n. 1, p.57-72, jan./jun. 2003 
tram ser o trabalho um traço cultural de definição entre imigrantes alemães e italianos e resgatam a dimensão histórica de conformação do ethos do trabalho entre estes imigrantes.

${ }^{14} \mathrm{Na}$ pesquisa de doutorado analisei também a identidade camponesa, não tratada neste artigo.

${ }^{15}$ Os trabalhos de Seyferth $(1976,1990)$ permitem visualizar a dimensão histórica de organização deste traço cultural entre imigrantes alemães e italianos e de sua mobilização como signo da identidade.

\section{REFERÊNCIAS}

BARTH, F. Grupos étnicos e suas fronteiras. In: POUTIGNAT, P; STREIFFFENART, J. Teorias da etnicidade. São Paulo: UNESP, 1998. p. 185-227.

BONIN, Jiani Adriana (1996). Mediações na recepção de TV: o "Campo e Lavoura" em Rio Fortuna - SC. Viçosa. 257 p. Dissertação (Mestrado em Extensão Rural) - Departamento de Economia Rural, UFV.

BONIN, Jiani Adriana. Identidade étnica e telenovela. 2001. 410 f. Tese (Doutorado em Ciências da Comunicação). Escola de Comunicações e Artes, Universidade de São Paulo, São Paulo.

BOURDIEU, Pierre. La distinción: criterio y bases sociales del gusto. Madrid: Taurus Humanidades, $1991.597 \mathrm{p}$.

BOURDIEU, Pierre. Esboços de uma teoria da prática. In: ORTIZ, Renato (org.). Pierre Bourdieu: Sociologia. São Paulo: Ática, 1994a. p. 46-81.

. Gostos de classe e estilos de vida. In: ORTIZ, Renato (org.). Pierre Bourdieu: Sociologia. São Paulo: Ática, 1994b. p. 82-121.

BUONANNO, Milly. El drama televisivo: identidad y contenidos sociales. Barcelona: Gedisa, 1999.

CERTEAU, Michel de. A invenção do cotidiano: artes de fazer. 2. ed. Petrópolis: Vozes, 1996.

COGO, Denise. Multiculturalismo e campo midiático: narrativas sobre as identidades nos 500 anos de Descobrimento do Brasil. In: MALDONADO et al. Mídias e processos socioculturais. São Leopoldo: Editora Unisinos, 2000. p.4377.

. O outro migrante: das estratégias de midiatização das migrações contemporâneas na mídia impressa brasileira. Ciberlegenda, Rio de Janeiro, n.10, p.1-24, 2002. Disponível em: $<$ http//www.ciberlegenda.br > Acesso em: 16/ $12 / 2002$.

FAUSTO NETO, Antônio. Comunicação e mídia impressa: estudo sobre a AIDS. São Paulo: Hacker Editores, 1999.

GARCÍA CANCLINI, Néstor. Culturas híbridas: estratégias para entrar e sair da modernidade. São Paulo: EDUSP, 1997a. 385 p.

. Cultura y comunicación: entre lo global y lo local. La Plata: Ediciones de Periodismo y Comunicación, 1997b. 133 p.

GOMES, Pedro; COGO, Denise. $O$ adolescente e a televisão. Porto Alegre: Unisinos/IEL, 1998.

Comun. Inf., v. 6, n. 1, p.56-71, jan./jun. 2003 
GONZÁLEZ, Jorge A. La cofradía de las emociones interminables: telenovela, memoria, familia. In: CANCLINI, Néstor Garcia (coord.). El consumo cultural en México. México: Consejo nacional para la cultura y las artes, 1991a. p. 295336

. La telenovela en familia: una mirada en busca de horizonte. Estudios sobre las culturas contemporáneas. Colima, v.4, n.11, p. 217-228, mar., $1991 \mathrm{~b}$.

. La cofradía de las emociones (in)terminables (parte primera): construir las telenovelas mexicanas. In: MAZZIOTTI, Nora (comp.) El espetáculo de la passión: las telenovelas latinoamericanas. Buenos Aires: Colihu, 1993a. p.1127.

. Metodología e sociología reflexivas: navegar plocelosos mares del pracer. Estúdios sobre las culturas contemporâneas. Colima, v.5, n.15, p. 209-226, mar., 1993b.

HALL, Stuart. A identidade cultural na pós modernidade. 3. ed. Rio de Janeiro: DP\&A, 1999.

KRUGER, Helmut. Notas sobre a identidade teuto-brasileira. Monografias Psicológicas, Rio de Janeiro, n. 10, p. 1-45, nov., 1995.

JACKS, Nilda. A recepção na querência: estudo da audiência e da identidade cultural gaúcha como mediação simbólica. 1993. 326 f. Tese (Doutorado em Ciências da Comunicação) - Escola de Comunicações e Artes, Universidade de São Paulo, São Paulo.

LEAL, Ondina Fachel. A leitura social da novela das oito. Petrópolis: Vozes, 1986.

LOPES, Maria Immacolata Vassallo de. Recepción de medios, clases, poder y estrutura: cuestones teórico-metodológicas de investigación cualitativa de la audiencia de los medios de comunicación de masas. Comunicación y sociedad, Guadalajara, n. 24, p. 85-96, mai./ago., 1995.

LOPES, Maria Immacolata Vassallo de et. al. Vivendo com a telenovela: mediações, recepção, teleficcionalidade. São Paulo: Summus, 2002. 394 p.

MALDONADO, Efendy. Produtos midiáticos, estratégias, recepção. A perspectiva transmetodológica. Ciberlegenda, Rio de Janeiro, n.9, p.1-15, 2002. Disponível em: $<$ http//www.ciberlegenda.br $>$ Acesso em: 19/11/2002.

MARTÍN BARBERO, J. La telenovela en Colombia: television, melodrama y vida cotidiana. Dialogos de la comunicación, Lima, n.17, p. 46-59, 1987.

Dos meios às mediações: comunicação, cultura e hegemonia. Rio de Janeiro: UFRJ, 1997.356 p.

MATA, María Cristina. De la cultura massiva a la cultura mediática. Diálogos de la comunicación, n. 56, p. 80-91, out. 1999. Disponível em <www.felafacs.org/ dialogos>. Acesso em: 20 de março, 2002.

OROZCO GÓMEZ, Guilhermo. Mapa para abordar las mediaciones en el proceso de recepción televisiva: una aproximación metodológica. Cuadernos de comunicación y practicas sociales, México, n.2, p.53-64, 1991.

Familia, televisión y educación en México: la "teoria educativa" de la madre como mediación en la recepción televisiva de los ninos. In: OROZCO, Guilhermo (comp.) Hablan los televidentes: estudios de recepción en varios países. México: Universidad Iberoamericana, 1992.p.11-32.

Comun. Inf., v. 6, n. 1, p.57-72, jan./jun. 2003 
Hacia una dialectica de la recepción televisiva: la estruturación de estrategias por los televidentes. Porto Alegre, mai., 1993. 27 p. Ponencia presentada en el Tercer Simposio Internacional de Comunicación. (mimeografado).

POUTIGNAT, Phillipe.; STREIFF-FENART, Joceline. Teorias da etnicidade. São Paulo: UNESP, 1998. 250 p.

RONSINI, Veneza Mayora. Televisión e identidad cultural. Diálogos de la comunicación, n.59-60, p. 102-111, outubro, 2001. Disponível em <www.felafacs.org/dialogos>. Acesso em: 20 de março, 2002.

STROHSCHOEN, Ana Maria. Mídia e memórias coletivas. 2003. $211 \mathrm{f}$. Tese (Doutorado em Ciências da Comunicação). Unisinos, São Leopoldo.

SEYFERTH, Giralda. Nacionalismo e identidade étnica: a ideologia germanista e o grupo étnico teuto-brasileiro numa comunidade do Vale do Itajaí. 1976. $308 \mathrm{f}$. Tese (Doutorado em Antropologia) - Universidade de São Paulo, Faculdade de Filosofia e Ciências Humanas.

SEYFERTH, Giralda. Imigração, colonização e identidade étnica. Revista de Antropologia, São Paulo, v.29, p.57-71, 1986.

1990. $103 \mathrm{p}$.

. Identidade camponesa e identidade étnica. Anuário Antropológico, Rio de Janeiro, n.91, p. 31-63, 1993.

VERÓN, Eliseo. Esquema para el analisis de la mediatizacion. Diálogos de la comunicación, n.48, p.9-17, 1997. Disponível em <www.felafacs.org/dialogos>. Acesso em: 20 de março, 2002.

ZVEIBIL, Sílvia Jane. Identidade étnica judaica: caracterização e processo de constituição. São Paulo. 1980. 163 p. Dissertação (Mestrado em Antropologia) - Faculdade de Filosofia e Ciências Humanas, USP.

Comun. Inf., v. 6, n. 1, p.56-72, jan./jun. 2003 